\title{
Canadian Forests: Past, Present and Future
}

by

\author{
Frances Wetton ${ }^{1}$
}

\begin{abstract}
The accepted ideas of any period are singularly those that serve the dominant economic interest. - John K. Galbraith
\end{abstract}

\section{Economy Based on Growth}

Canada is close to the end of nearly a century of dynamic growth and must soon face the full impact of a finite supply of resources. Already we have felt ominous supply shocks in strategic resources and have all but run out of "back forties" in which to expand wood fibre exploitation. Our society is well adjusted to growth. All the habits, institutions, technologies and ideologies which have survived are those which have been adaptable to expansion (1). In the forest section we can trace this phenomena in the rise of strong industrial interests in resource exploitation, in the expediencies and strategies used by governments in developing a nation, and in the symbolic relationship which has been established between government and industry in the drive toward economic growth.

Ever since Europeans first settled in Canada our economic, political and social development has been inexorably linked to the forests. It could not have been otherwise. The forest was there - nearly everywhere one turned there were trees: trees to be cursed or blessed, burned or chopped, granted or sold, driven or rafted, squared or sawn, protected or devastated, leased or licenced, planed or chipped, and sometimes enjoyed just for being there. It was a resource not only with which to build homes but which was ripe for exploitation in export trade, adaptable to water transportation (and to shipbuilding itself) and later to rail and road. It offered a wide range of investment possibilities, and the rising demand for forest products in England and later the United States generated profits in both large and small mills that were the catalysts for accelerated development in other sectors of the economy. Indeed, it has been said that lumber manufacturing and shipbuilding led the way to Canadian industrialization, and paper was the advertising medium that propelled the burgeoning manufacturing industries of North America (2). Forest products have continued to dominate Canadian trade and currently contribute far more to a favourable balance of trade than any other resource.

Forest products have been highly significant in the evolution of Canadian-American relations. The rising demand for Canadian lumber in the United States was the main reason for the Reciprocity Treaty of 1854 , which initiated the major Canadian trade shift from England to the United States. It was also the basis for the incredible growth of American investment, first in the Canadian forest sector and later in other industries (3).

Politically, the forest resource provided a rapid means of reinforcing the viable economy established with the early fur trade. In addition, the government received a continuous and often bountiful source of revenue from sales and other fees, together with a basis for patronage and government corruption. The political frame was built around the early exploitation of forests and other natural resources, export

${ }^{1} \mathrm{Dr}$. Wetton is a forest economist and president of E.A.F. Wetton and Associates, 4112 Longview Drive, Victoria, BC. V8N 2K7 trade, regionalism, and strong government influence in development. Governments favoured an elite group, encouraged foreign investment, and provided or endowed transportation and power systems. These factors greatly influenced later policies, and are evident in the terms of Confederation, the Canadian National Policy, and much legislation since (4).

In retrospect, the decisions made at Confederation and in the National Policy were the necessary ones in a growth strategy to develop a nation and to attain industrial maturity. These goals, however, cannot be separated from the means by which they were achieved, and Canadians are obliged to cope with the undesirable side effects. The early political frame was built during a rapid exploitation period. Policies, expedient at the time but now obsolete and unwieldy, are not easily changed in the fairly rigid frame of decisionmaking which has evolved. For example, very little provision has been made to restock accessible forests. The depletion of this resource has led to uneconomic industrial plants, towns, and transportation systems which must often be subsidized. Railways, once the prime instruments for nationbuilding, have lost much of their dominance and appear over-developed. Another problem originated from the strong dependence on resource revenue by colonial administrators. Their desire for continued regional control over resources became entrenched in the terms of Confederation. This split in the ownership and jurisdiction of the forest sector between levels of government has led to serious federal-provincial conflicts.

At the time that investment capital was needed to promote national development it simply wasn't available in Canada at the levels required. Our heavy reliance on external capital, however, has created certain problems which are intensified by the continuous competition among provinces for foreign capital in their development schemes. Currently a very high proportion of Canadian corporations are American-controlled, particularly in resource exploitation and manufacturing (5). The forest sector, by comparison, is considered to be relatively low at $40 \%$ total foreign ownership, although highly-manufactured forest products have much higher percentages. Many advantages and disadvantages are seen in the unique CanadianAmerican connection which has extended beyond mere trading and investing, but that analysis must be left for another paper. What is significant to our discussion is to note that the foreign capital inputs required in the initial stages of a country's development have not decreased in Canada, as is usual in the maturing process, and have resulted in remarkably high levels of foreign ownership and control of natural resource sectors. This has most certainly retarded the rate of secondary industrialization and technological development in our economy.

Each era has passed down a legacy of ideas, values and policies which have gradually become entrenched. These views have been strongly influenced by the economic and political conditions and the expediencies of the time, but 
also, and often even more significantly, these views have been coloured by the mould in place, by a series of past decisions, and by the established structures for implementing policy. In Canada the whole process of policy decisionmaking has become increasingly complex, and now usually allows only incremental alterations, rarely yielding to dramatic or major changes. Thus, historic decisions have had and will continue to have a powerful impact on policy direction.

In the forest sector our legacies have been policies which exploited the extensive virgin forest, used it as a vehicle for economic growth and for government revenue, adopted Crown ownership and regional jurisdiction, encouraged foreign investment in exploitation, maintained low economic rents for the resource to encourage industry, and allowed the continued export of low-manufactured products. Such policies did little to renew the resource, to strengthen Canadian industrial control and diversification or to inspire the development of Canadian technology.

\section{Post-Industrial Scenarios}

Several post-industrial scenarios have been formulated. All require major modifications of our current system. One group proposes a continuation of the capitalist freeenterprise system, but with greatly increased technology to extend resources and to protect the environment. This group cherishes the notion that our economy is on the threshold of incredible abundance and leisure due to advancements in technology. Other groups envisage societies based on various forms of socialism and égalitarianism, but with constraints on consumption through strong government intervention in production and in resource allocation. A third group, the quaternary culture, advocates a nonmaterialistic approach which requires major voluntary changes in our value system.

The capitalist system has served our society well during the rapid growth period. No other system had the powerful incentives necessary to draw investment and mobilize innovation in order to create our massive productive forces. It requires that instruments of production be in constant revolution to secure advantages in the highly competitive milieu. The system is also self-perpetuating in that people are awarded for playing within the structure rules, and there is no inclination to reshape them. It is argued that capitalism will fail not because of economic failure but rather through its very success, which has produced self-defeating characteristics. The fact of physical limitation to expansion, too, puts a brake on this system which is entirely dependent on growth. Further, capitalism undermines itself because of the failures in the elaborate exchange devices and institutions which evolve from it and often result in unemployment and depression (6).

The quaternary culture emphasized personal and selfserving activities rather than the traditional primary, secondary, and tertiary activities oriented toward extraction, production, and distribution of goods for mass consumption. It is the embodiment of Rostow's famous "beyondconsumption" stage in which a value system evolves from social rather than economic accounting (7). In this society, the voracious consumption which is part of the materialism ethic will give way to less consumptive activities such as skills in sports, outdoor recreation, arts, and horticulture. Reading, discussion, debating, and politicking will replace some of the current pastimes which require high expenditures of energy and other natural resources. It has been dubbed the "knowledge" society - a renaissance of the mind. It may be that we will choose not to serve Galbraith's "dominant economic interests".

\section{Forests In Our Future?}

We have seen how vital the forest resource has been to Canadian development in the past. What is the role of forests in our future? Nothing is certain. I am no better able to answer "Watchman, what of the night?" than Dick Orchard in his "Preposterous Prognosis" to the Canadian Institute of Forestry in 1959:

The programme committee instructs me to switch on the lights in the pitch dark future and say how, where,

and why we are going, and when we will get there (8).

However, we can reasonably expect that forests will be a part of resource, energy, and environmental plans in any scenario.

It would appear that Canada will be able to harvest some 225 million cubic metres of wood annually by the year 2000 , based on current AAC estimates. These predictions, however, rely on sketchy resource information and do not always take into account the remote and often uneconomic location of timber supplies nor the incidence of low-grade or undesirable species. Also, the forest land base is not static:

The future AAC's on lands in all classes of ownership will depend on changes in owners' goals. Provincial governments' forest development and use goals are becoming increasingly diverse as more demands are placed on the forest estate. In order to cope with changing goals, many provincial governments have struck Royal Commissions and task forces to investigate evolving problems and to make recommendations for policy change (9).

The demand for traditional wood products will continue. Trends in world consumption suggest that pulp and paper will increase by 3.5 to 4.3 percent, and softwood lumber by 1 to 2 percent annually (10). Canada's share of this world demand will depend to a large extent on the competitiveness of forest industries. A relatively strong resource base does not imply cheap delivered wood inputs. The cost of delivered wood in the Interior of British Columbia and southern United States was well below that in other regions in North America in 1976, but costs in Quebec, Ontario, and coastal British Columbia were considerably higher (11). Estimated costs in Brazil and Southwest Asia were below North American levels. Transportation and labour costs are generally higher in Canada than in the United States, but energy costs are lower. American producers have added advantages in established infrastructure, access to markets, and more productive forest land. Western Europe is close to consumers, but faces comparatively high wood costs and the physical limits to the resource. South America's low wood costs are offset by the high costs required for developing infrastructure and access and its disturbing political instability. Despite uncertainties in the investment climate in Canadian forest industries, this country has the social order in which even the most timid capitalist is willing to invest.

Future changes in all these factors will alter the comparative advantage of each country. Wood costs will undoubtedly rise everywhere as the resource becomes scarcer or is renewed at a high cost. Canada's relative position in wood supply is better than in many developed countries because of the potential for expansion, but we may not be as affluent as would appear. Certainly, effort must be directed toward increasing intensive management on productive, accessible sites if we expect to maintain or expand our forest industries. 
The trend in wood product diversification will continue, but may not be as great in Canada as elsewhere. The potential use of biomass energy is under careful study. It has been estimated that there are tremendous untapped energy resources in logging and milling residues and in uneconomic (from fibre viewpoint) forests. Most of the proposed conversion methods are currently uneconomic, but with rising oil prices may soon become feasible. For example, the threshold level for methanol vehicle fuel is $\$ 35 . / \mathrm{bar}$ rel of oil and for synthetic gasoline is $\$ 52 . /$ barrel of oil. Both may be produced from forest biomass (12). Currently, a firm in Prince Edward Island has developed a densified wood pellet from shredded wood which is 10 per cent cheaper than comparable energy from oil at world prices. It is argued that this method should be subsidized as much as foreign oil imports to Canada. The energy potential of wood will also be constrained by the pollution generated. If technologies can be found which limit emissions, the development of safe, renewable energy holds great promise.

Within a post-industrial scenario emphasizing quaternary activities, forests would play increased social and cultural roles. Recreational and non-industrial uses of forest land would assume greater value in the trend to less consumptive demands. High environmental quality standards would constrain various processes and force new non-polluting technologies and products. This scenario would not reduce forestry to a parochial pastime by any means, but would reallocate the resource under a new value system. Even on our present course, public interest and concern about nonfibre outputs from the forest are predicted to increase significantly in the decades ahead.

\section{Coping With Our Problems}

One of the most difficult problems Canadians will have to face is reconciling industrial growth and environmental protection. Our society has been conditioned to a sense of wellbeing which is dependent on the expansion of production and the exploitation of resources and is disappointed if the rate falters. Those who defend economic growth rest their case on the close association between rising per capita GNP and rising levels of human welfare, despite all the misallocations and environmental mistakes which have been made in the process of growth. Everything about us emphasizes growth. Our free enterprise economy encourages want-creating activities in the market, and our material appetites appear to be insatiable.

Our rate of growth has required the progressive exploitation of resources and has led to a deterioration of the environment. Damage follows from both the production and consumption of goods. Indeed, some writers view environmental decay as an integral part of the whole process of economic growth. Pollution levels have increased dramatically since World War II because of basic changes in industrial and agricultural production and in transportation. Technological processes which were fairly benign to the environment have been replaced by ones which sharply increase the ratio of pollutant emitted to goods produced. It is argued that these changes have caused far more damage than increased population or per capita consumption (13).

There is widespread and growing awareness of this deterioration. Environmental interest groups have expanded during the last two decades and include many publicminded citizens. They question our industrial growth path which appears to require rapid resource use and which results in a high level of pollution. Currently, serious limitations are present in both the Canadian legal system and in government mechanisms for public participation in decisions involving environmental protection and resource management (14).

Industrial interest groups are undoubtedly in favour of growth, but they are neither good nor bad in their perception of the environment. They have simply been responsive to the demands of our society. The consequent patterns of development have followed because the majority of citizens have not felt strongly enough about the environment to want to make major changes in the parameters of production. However, forest industries have had to accept the higher production costs imposed by certain required pollution abatement facilities and forest operators have had to adapt their woodland activities to various environmental guidelines, but these fall short of preventing deterioration.

Some see a solution to the problem in absolute terms, that is, growth versus no-growth. Many are opposed to a zero-growth stance because of its psychological effect on society. It is believed that our many human and social difficulties would worsen in a stationary state:

It is an alarming commentary on the intellectual instability of our times that today mileage can be made with the proposal to stop America dead in her tracks. Don't we know which way is forward? ... Growth is a substitute for equality of income. So long as there is growth there is hope, and that makes a large income differentials tolerable (15).

We should bear in mind that much of the environmental damage associated with growth is not due to growth itself, but is a function of the way we grow, the nature of technology, and the forms of production (16). A major concern is whether corrective mechanisms can be found which are capable of guiding the economy along some safe equilibrium path of growth. One route might be to force production into redirected channels and prohibit dangerous activities. Another route would force producers to absorb all disposal costs. Growth advocates maintain that the environment will be better served if the economy continues to grow. "Nothing could cut more dangerously into the resources that must be devoted to the Great Cleanup than an attempt to limit resources available for consumption"' (17). Not all, however, will agree that resources from expanded growth will, in fact, be diverted to an environmental clean-up.

Most people are unaccustomed to thinking about the role of biological systems in the economy and the critical balances which are being disrupted by our relentless global economic expansion, which has been estimated at 4 per cent per year. It has been demonstrated that the functions of many of the interrelated systems have become impaired. Should any collapse, the effect would be cumulative. We can easily trace the tremendous influence of forests on Canadian economic and social evolution. The biological impact of our extensive forests, although not as visible, has been just as important. The policies that are followed in forest resource management, industrial development, and environmental protection will determine, in a large measure, the future quality of our lives. Moreover, Canadians are accountable not only to themselves, but to the larger global community because environmental problems are not contained within national boundaries. As a responsible and mature nation, Canada is obliged to take a broad perspective and to weigh the consequences of her decisions very carefully.

The crisis facing Canadians is as much psychological and political as it is economic and environmental. There is an acute sense of frustration and cynicism concerning government. Perhaps the growth of a giant social service bureaucracy has stripped us of natural confidence and an ability to cope with crisis. Based on recent experiences, Canadians are beginning to doubt that any current government can fine-tune the economy to even out business cycles and guarantee a never-ending expansion in production. Too much government authority and too many regulations have defused individual citizen responsibility and have worked against accountability. No one is to blame and everyone is 
to blame for policies which waste our resources and do not reflect our aims. Politicians might consider their many regulatory schemes with added care if they recall an ancient Greek system of law-making. It was the custom that when a man proposed a law in the assembly he stood on a platform with a rope around is neck. If his law passed they removed the rope; if it failed, they removed the platform.

\section{Conclusion}

Our survival and future now depend on how well we can make the adjustment to a higher stage of development. There is a tendency to cling to traditional mechanisms for dealing with shortages, such as price changes and substitutes, and a marked reluctance to consider any fundamental change outside the frame of accepted givens. Part of our growing crisis is that we have considered only vigorous growth paths and have devised systems which concentrate on a narrow range of options. Are we capable of making the necessary changes in our economy (and for us, the forest sector in particular) so that we can continue to move forward but on a more promising course than the one we are on now? Canada is in a difficult position. Any adjustment to a post-industrial stage is complicated by many factors, not the least of which is that Canada entered the mature economic level of a "developed" country without sufficient industrial diversification and with largely imported technology. Without these measures of independence it will be difficult indeed for her to chart her own destiny.

It has been said that "the dilemma of our age has no precedent, no parallel experience to guide it" (18). Our growth path has been based on abundance and an environment which could absorb our wastes. These parameters have been changed. Perhaps the only way to cope with this altered scenario is to introduce a new system of values, to re-assemble the political structure in some fundamental way, to undergo "a rare historic convulsion to redistribute forces" (19). In this case, our usual incremental 'muddling through' would not be sufficient for the major transformation required. Ben Johnson said that survival "focused the mind wondrously". We can only hope that when our society reaches this point of choice it will see clearly what its true psychological, social, and economic values are, and how they can be accommodated within the constraints of the resource base. Until then, as Canadian citizens and as foresters, we might try:

To know ourselves, where we are in time where we are going, what our responsibilities are to ourselves and to others. .

Thomas Symons

\section{Woodlot Service (1978) Ltd.}

"All Matters Pertaining to Forestry"

GORDON B. YOUNG, B.Sc.F., M.F. Registered Professional Forester

320 Maple Street

Fredericton, N.B.
Bus.: 506 - $472-3396$

Home: 506 - 472-7721

\section{References}

1. Boulding, K.E. 1973. The economics of love and fear. Wadsworth Publishers, Belmont, Cal.

2. Lower, A.R.M. 1938. The North American assault on the Canadian forest. Greenwood Press, New York.

3. Defebaugh, J.E. 1906. History of the lumber industry of America. Vol. I. 2nd ed. The American Lumberman, Chicago.

4. Nelles, H.V. 1974. The politics of development: Forests, mines and hydro-electric power in Ontario, 1849-1941. Macmillan of Canada, Toronto.

5. Clement, W. 1977. Continental corporate power: economic linkings between Canada and the United States. McClelland and Stewart Ltd., Toronto.

6. Boulding, op. cit., Chapter 8.

7. Rostow, W.W. 1962. The stages of economic growth: a noncommunist manifesto. Cambridge University Press, New York.

8. Orchard, C.D. 1959. Preposterous prognosis. For. Chron. 35(4):275-281.

9. Aird, K.L. and J. Ottens, 1979. The outlook for timber utilization in Canada to the year 2000. Policy, Development and Analysis Branch, Canadian Forestry Service, Environment Canada. Forestry Tech. Report 29. p. 189.

10. Reed, F.L.C. 1979. "Realizing the economic potential of Canada's forest resource". For. Chron. 55(6):217-221.

11. Canada, Department of Trade and Commerce. 1978. Review of the Canadian forest products industry. Forest Products Group. Supply and Services Canada, Cat. No. Id 31-69/1979. p. $167-185$

12. Canadian Resourcecon Ltd. 1978. Economic analysis of synthetic liquid fuels. Prepared for the Advisory Group on Synthetic Liquid Fuels, Ontario Ministry of Energy. p. 8.

13. Commoner, B. 1973. Ecology and social action. The Horace M. Albright Conservation Lectureship at the University of California, School of For. \& Cons., March 15, 1973.

14. Elder, P.S. 1975. Environmental management and public participation. Canadian Environmental Law Research Foundation, Toronto.

15. Wallich, H.C. 1972. "Zero growth". Newsweek, January 24 , 1972.

16. Hanks, E.M., A.D. Tarlock and J.L. Hanks. 1974. Environmental law and policy. West Publishing Co., St. Paul.

17. Wallich, op. cit.

18. Donald, D.H. cited in Hutchison, B. "There's little we can do" Victoria Times. April, 1978.

19. Newman, P.C. Editorial in MacLean's. November 27, 1978.

\section{MARKETING TECHNICIAN Reforestation and Reclamation Equipment}

As a result of growth,

Largest distributor of Reforestation and Revegetation Machinery in Canada seeks qualified individual for marketing of wide variety of Site Preparation, Reclamation and Nursery Machinery and equipment.

If you have a post secondary degree in Forestry or Forest Engineering, consider joining our team.

Technical and practical Mechanical background, and experience in Marketing are assets, but not absolutely necessary.

Complete training program provided.

Territories Available: Ontario and Western Canada. Our Compensation package is most attractive.

For further information or how to join one of the fastest growing companies in the Forest Industry, please send resume to:

CANADIAN FORESTRY EQUIPMENT LTD. 2567 Drew Road Mississauga, Ontario L4T 1G1 